\title{
Associated Maternal and Fetal Factors of Fetal Congenital Heart Diseases Diagnosed by Fetal Echocardiography
}

\section{Yanping Ruan}

Department of Ultrasound, Maternal-fetal Medicine Research Consultation Center, Beijing Anzhen Hospital, Capital Medical University

\section{Zan Xie}

the Affiliated Yantai Yuhuangding Hospital of Qingdao University

Xiaowei Liu

Department of Ultrasound, Maternal-fetal Medicine Research Consultation Center, Beijing Anzhen Hospital, Capital Medical University

Yihua He ( $\nabla$ heyihuaecho@hotmail.com )

Department of Ultrasound, Maternal-fetal Medicine Research Consultation Center, Beijing Anzhen Hospital, Capital Medical University

\section{Research Article}

Keywords: Congenital heart diseases, fetal, Odd ratio, Factor

Posted Date: April 19th, 2022

DOI: https://doi.org/10.21203/rs.3.rs-1408405/v2

License: (9) This work is licensed under a Creative Commons Attribution 4.0 International License. Read Full License 


\section{Abstract \\ Objective}

Current studies have suggested that fetal congenital heart diseases (CHDs) are caused by various factors. However, few data is available with respect to the aspect in China. This study aimed to detect associated maternal and fetal factors of fetal CHD in a large sample in China.

\section{Study Design:}

Pregnant women who underwent fetal echocardiography $(\mathrm{N}=5024)$ were recruited in our hospital between May 2018 and September 2019. Of these, 875 pregnant women had fetuses with CHD. The maternal sociodemographic and lifestyle characteristics and some fetal factors were obtained. We used forward stepwise logistic regression analysis to assess the associations of fetal CHD with various factors.

\section{Results}

Among the fetal CHD group ( $\mathrm{N}=875)$, critical CHDs account for $27 \%$, of which Tetralogy of Fallot is the most $(7.1 \%)$, followed by coarctation of aorta (4.0\%), Double-outlet right ventricle $(2.9 \%)$. The forward stepwise logistic regression models revealed that gravidity $(\mathrm{OR}=1.32,95 \% \mathrm{Cl} 1.21-1.43, \mathrm{P}=0.000)$, upper respiratory tract infection during early pregnancy $(\mathrm{OR}=1.30,95 \% \mathrm{Cl} 1.04-1.63, \mathrm{P}=0.021)$, mental stress during early pregnancy $(\mathrm{OR}=2.87,95 \% \mathrm{Cl} 1.35-5.92, \mathrm{P}=0.006)$, single umbilical artery $(\mathrm{OR}=2.46,95 \% \mathrm{Cl}$ $1.24-4.85, \mathrm{P}=0.010)$, and parental smoking $(\mathrm{OR}=1.20,95 \% \mathrm{Cl} 1.00-1.45, \mathrm{P}=0.048)$ are positively associated with an increased risk of fetal CHD.

\section{Conclusion}

We identified two maternal factors and two fetal factors positively associated with fetal CHD.. These findings suggest that it is important to strengthen healthcare and prenatal counseling for women with these factors.

\section{Introduction}

Congenital heart disease (CHD) results from a defect in the structure and function of the heart caused by abnormal heart development during the fetal period. CHD is a large, rapidly emerging global problem in child health; in the Global, regional, and national burden of CHD Study 2017, the global prevalence of CHD is estimated to be nearly $1.8 \%$ [1]. In China, the prevalence of CHD is 8.98 per 1000 live births [2], significantly higher than global level, definitely with much higher disease burden of CHD. It is also one of 
the leading causes of morbidity and mortality in the perinatal and infant periods [3, 4]. As for fetal CHD, the prevalence cannot be reasonably estimated due to prenatal detection rates and intrauterine loss.

Current research has shown that many factors are associated with an increased risk of CHD in the fetus, including genetic [5] and maternal or fetal factors, both of which are addressed for their associations with various risks in the Scientific Statement from the American Heart Association (AHA) [6]. However, available information about the association of maternal and fetal factors with CHD is limited in China, especially for fetal CHD. Therefore, this study is conducted to assess the factors that influence fetal CHD in a large sample size in China.

\section{Materials And Methods}

\section{Study design and participants}

Our study was a retrospective population-based study of 5024 pregnant women who underwent fetal echocardiography from May 2018 to September 2019 at our center. All data are kept in our center's maternal-fetal medicine database. Fetal ages were calculated from the last menstrual period. Enrollment criteria included (1) relatively complete data, and (2) a fetal heart examination and diagnosis of fetal CHD meeting the specifications for the diagnosis and treatment of fetal cardiac disease released by AHA[6]. The exclusion criteria were including duplicate cases, subjects with more than $50 \%$ missing variables, variables with more than $50 \%$ missing data, and variables with only one assignment in the population, such as administration of angiotensin-converting enzyme inhibitors (ACEI), retinoic acid, lithium, anticonvulsants or selective serotonin reuptake inhibitors, and history of consanguinuous marriage. This study was approved by the Ethics Committee of Beijing Anzhen Hospital, Capital Medical University (2022060X), and written informed consent was signed by all participants.

\section{Data collection}

We acquired the following information through questionnaires while patients were waiting to be examined: (1) maternal sociodemographic and lifestyle characteristics: including age, comorbidities (diabetes, upper respiratory infection during early pregnancy, anemia, connective tissue diseases with anti-SSA/SSB positive and thyroid disease), mental stress during early pregnancy, medication exposure, history of CHD, consanguineous marriage, employment and bad habits of subjects and spouses, occupational radiation exposure, pet-keeping and indoor decoration. Early pregnancy usually refers to the first trimester of pregnancy. (2) pregnancy-related characteristics: including the gravidity, history of induced labor or spontaneous abortion, fertilization way, progesterone use and genetic testing of this pregnancy, and gestational weeks (GWs), (3)fetal factors, including single or twin fetuses, fetal hydrops, single umbilical artery (SUA), persistent right umbilical vein (PRUV), and results of fetal echocardiography. Anemia was defined as hemoglobin $(\mathrm{g} / \mathrm{dL})$ and hematocrit (percentage) levels below $11 \mathrm{~g} / \mathrm{dL}$ and $33 \%$, respectively, in the first trimester; $10.5 \mathrm{~g} / \mathrm{dL}$ and $32 \%$, respectively, in the second trimester; and $11 \mathrm{~g} / \mathrm{dL}$ and $33 \%$, respectively, in the third trimester [7]. Smokers were defined as smoking ( $\geq 10$ cigarettes/d) and passive smoking status of pregnant women from the first 3 months before 
pregnancy to the first 3 months of pregnancy (with spouse's smoking $\geq 10$ cigarettes/d). Drinkers were defined as alcohol consumption of 3 drinks/week or 1 drink/d for 6 months prior to pregnancy for spouses or /and during pregnancy for pregnant women, and 1 drink was equivalent to $12 \mathrm{~g}$ alcohol.

\section{Diagnosis of Fetal CHD}

The outcome variables were any form of fetal CHD. The diagnosis of fetal CHD was based on fetal echocardiography using a Voluson E8-RAB4-8 machine equipped with a 2- to 8-MHz transducer (GE Healthcare, Little Chalfont, United Kingdom). The acquisition of fetal echocardiographic images was performed according to the guidelines and standards of the AHA [6] and the International Society of Ultrasound in Obstetrics and Gynecology (ISUOG) [8].

Fetal echocardiography was performed by experienced associate chief physicians and chief physicians, and diagnoses were then made by these individuals based on grayscale and color images and pulse wave Doppler according to multiple section screening, including four-chamber, left and right ventricular outflow tract (LVOT and RVOT), three-vessel (3V), and three vessels and trachea (3VT) views as well as sagittal views of the superior and inferior vena cavae, aortic arch, and ductal arch. In our center, we have been confirmed the diagnostic accuracy of fetal echocardiography by comparing with autopsy findings. The major cardiovascular malformations in about $98.8 \%$ of cases were accurately diagnosed by fetal echocardiography [9].

\section{Statistical analysis}

Continuous variables with a Gaussian distribution are expressed as the mean \pm standard deviation and were compared using a t-test between the two groups, while non-Gaussian variables are expressed as the median (interquartile range, IQR) and were compared using a non-parameter test between the groups. Noncontinuous variables are expressed as percentages (\%). Chi-square tests were performed to compare the variables between the two groups. Multivariate logistic regression analyses using forward stepwise (likelihood ratio) were performed to evaluate the factors independently associated with the outcome variables. The independent variables included the maternal and fetal factors mentioned above. The odd ratio (OR) and $95 \%$ confidence interval $(\mathrm{Cl})$ were used to express the magnitude of the association between outcome and risk factors. Statistical significance was achieved with a two-tailed value of $\mathrm{P}<$ 0.05. The Statistical Package for Social Science, version 22 for Windows (SPSS22.0) was used for statistical analyses.

\section{Results}

\section{Baseline characteristics in the normal group and the fetal CHD group}

Among all the participants, 875 pregnant women had fetal CHD fetuses, while 4149 women had normal fetuses. The mean age for the pregnant women and their spouses in the CHD group was 30.36, 31.79 
years old, younger than that in the normal group, 31.03 or 32.65 years old, respectively (all $P<0.05$ ). The gestational ages for both groups were about 26 weeks. The subjects in CHD group had more pregnancies than the normal group (all $\mathrm{P}<0.05$ ). The proportion of spontaneous abortion, induced labor, childbirth, progesterone use, upper respiratory tract infection in early pregnancy, mental stress during pregnancy, and spouse's current smoking and drinking was higher in the CHD group than in the control group(all $\mathrm{P}<$ 0.05). In addition, CHD group had a higher rate of fetal hydrops and amniotic fluid abnormality than the control group (all $\mathrm{P}<0.05)$ (Table 1). 
Table 1

Baseline characteristics of the normal group and the fetal CHD group

\begin{tabular}{|c|c|c|c|}
\hline Variables & Normal group & CHD group & $\begin{array}{l}\text { P- } \\
\text { value }\end{array}$ \\
\hline $\mathrm{N}$ & 4149 & 875 & \\
\hline Age & $31.03(4.25)$ & $30.36(4.27)$ & $\dot{0.001}$ \\
\hline Gestational Weeks & $26.08(2.82)$ & $26.77(3.82)$ & $\begin{array}{l}<.001 \\
0.001\end{array}$ \\
\hline Parental age & $32.65(5.07)$ & $31.79(4.79)$ & $\begin{array}{l}<.001 \\
0.001\end{array}$ \\
\hline Gravidity & $\begin{array}{l}2.00(1.00- \\
2.00)\end{array}$ & $\begin{array}{l}2.00(1.00- \\
3.00)\end{array}$ & 0.031 \\
\hline Spontaneous abortion & & & $\begin{array}{l}<.001 \\
0.001\end{array}$ \\
\hline No & $2810(70.51 \%)$ & $533(63.00 \%)$ & \\
\hline Yes & $1175(29.49 \%)$ & $313(37.00 \%)$ & \\
\hline Induced labor & & & 0.003 \\
\hline No & $3848(98.46 \%)$ & 795 (96.95\%) & \\
\hline Yes & $60(1.54 \%)$ & $25(3.05 \%)$ & \\
\hline Delivery history & & & 0.002 \\
\hline No & $2775(70.38 \%)$ & $542(64.83 \%)$ & \\
\hline Yes & $1168(29.62 \%)$ & $294(35.17 \%)$ & \\
\hline Fertilization way & & & 0.735 \\
\hline Natural conception & $3829(95.87 \%)$ & $818(96.12 \%)$ & \\
\hline In-Vitro Fertilization & $165(4.13 \%)$ & $33(3.88 \%)$ & \\
\hline Progesterone use & & & 0.026 \\
\hline No & $3248(83.30 \%)$ & $664(80.10 \%)$ & \\
\hline Yes & $651(16.70 \%)$ & $165(19.90 \%)$ & \\
\hline Down's or noninvasive DNA testing & & & 0.419 \\
\hline Low risk & $3219(95.69 \%)$ & $685(95.01 \%)$ & \\
\hline High risk & $145(4.31 \%)$ & $36(4.99 \%)$ & \\
\hline CHD: congenital heart disease & & & \\
\hline
\end{tabular}




\begin{tabular}{|c|c|c|c|}
\hline Variables & Normal group & CHD group & $\begin{array}{l}\mathrm{P} \text { - } \\
\text { value }\end{array}$ \\
\hline Anemia & & & 0.76 \\
\hline No & $4129(99.61 \%)$ & $870(99.54 \%)$ & \\
\hline Yes & $16(0.39 \%)$ & $4(0.46 \%)$ & \\
\hline Thyroid disorders & & & 0.437 \\
\hline No & $4113(99.13 \%)$ & $865(98.86 \%)$ & \\
\hline Yes & $36(0.87 \%)$ & $10(1.14 \%)$ & \\
\hline Upper respiratory tract infection in early pregnancy & & & $\begin{array}{l}< \\
0.001\end{array}$ \\
\hline No & $3540(85.32 \%)$ & $707(80.80 \%)$ & \\
\hline Yes & 609 (14.68\%) & $168(19.20 \%)$ & \\
\hline Autoimmune disease & & & 0.603 \\
\hline No & $4108(99.01 \%)$ & $868(99.20 \%)$ & \\
\hline Yes & $41(0.99 \%)$ & $7(0.80 \%)$ & \\
\hline Diabetes mellitus & & & 0.886 \\
\hline No & $4104(98.92 \%)$ & $865(98.97 \%)$ & \\
\hline Yes & $45(1.08 \%)$ & $9(1.03 \%)$ & \\
\hline Nonsteroidal anti-inflammatory drugs & & & 0.925 \\
\hline No & $4129(99.57 \%)$ & $871(99.54 \%)$ & \\
\hline Yes & $18(0.43 \%)$ & $4(0.46 \%)$ & \\
\hline Vitamin $\mathrm{K}$-antagonist & & & 0.961 \\
\hline No & $4140(99.88 \%)$ & $874(99.89 \%)$ & \\
\hline Yes & $5(0.12 \%)$ & $1(0.11 \%)$ & \\
\hline Maternal smoking & & & 0.987 \\
\hline No & $4138(99.78 \%)$ & $873(99.77 \%)$ & \\
\hline Former smokers & $5(0.12 \%)$ & $1(0.11 \%)$ & \\
\hline Current smokers & $4(0.10 \%)$ & $1(0.11 \%)$ & \\
\hline Maternal drinking & & & 0.087 \\
\hline
\end{tabular}




\begin{tabular}{|c|c|c|c|}
\hline Variables & Normal group & CHD group & $\begin{array}{l}\mathrm{P} \text { - } \\
\text { value }\end{array}$ \\
\hline No & $4139(99.83 \%)$ & $873(99.77 \%)$ & \\
\hline Former drinkers & $7(0.17 \%)$ & $1(0.11 \%)$ & \\
\hline Current drinkers & $0(0.00 \%)$ & $1(0.11 \%)$ & \\
\hline Parental smoking & & & 0.013 \\
\hline No & $3897(93.97 \%)$ & $800(91.43 \%)$ & \\
\hline Former smokers & $30(0.72 \%)$ & $12(1.37 \%)$ & \\
\hline Current smokers & $220(5.31 \%)$ & $63(7.20 \%)$ & \\
\hline Parental drinking & & & 0.031 \\
\hline No & $3986(96.12 \%)$ & $824(94.17 \%)$ & \\
\hline Former drinkers & $40(0.96 \%)$ & $14(1.60 \%)$ & \\
\hline Current drinkers & $121(2.92 \%)$ & $37(4.23 \%)$ & \\
\hline $\begin{array}{l}\text { Spouse's medication use during preparation for } \\
\text { pregnancy }\end{array}$ & & & 0.014 \\
\hline No & $4102(99.11 \%)$ & $857(98.17 \%)$ & \\
\hline Yes & $37(0.89 \%)$ & $16(1.83 \%)$ & \\
\hline Mental stress during early pregnancy & & & $\begin{array}{l}< \\
0.001\end{array}$ \\
\hline No & $4120(99.32 \%)$ & $858(98.17 \%)$ & \\
\hline Yes & $28(0.68 \%)$ & $16(1.83 \%)$ & \\
\hline Occupational radiation exposure & & & 0.099 \\
\hline No & $4132(99.61 \%)$ & $868(99.20 \%)$ & \\
\hline Yes & $16(0.39 \%)$ & $7(0.80 \%)$ & \\
\hline Family history of $\mathrm{CHD}$ & & & 0.828 \\
\hline No & 4140 (99.81\%) & $872(99.77 \%)$ & \\
\hline Yes & $8(0.19 \%)$ & $2(0.23 \%)$ & \\
\hline Multifetation & & & 0.238 \\
\hline No & 4060 (97.90\%) & $851(97.26 \%)$ & \\
\hline
\end{tabular}

CHD: congenital heart disease 


\begin{tabular}{|c|c|c|c|}
\hline Variables & Normal group & CHD group & $\begin{array}{l}\mathrm{P} \text { - } \\
\text { value }\end{array}$ \\
\hline Yes & $87(2.10 \%)$ & $24(2.74 \%)$ & \\
\hline Fetal hydrops & & & $\begin{array}{l}< \\
0.001\end{array}$ \\
\hline No & $4135(99.81 \%)$ & $867(99.09 \%)$ & \\
\hline Yes & $8(0.19 \%)$ & $8(0.91 \%)$ & \\
\hline amniotic fluid volume & & & 0.009 \\
\hline Normal & $4103(99.37 \%)$ & $860(98.51 \%)$ & \\
\hline Abnormal & $26(0.63 \%)$ & $13(1.49 \%)$ & \\
\hline Pet-keeping & & & 0.608 \\
\hline No & 3974 (95.85\%) & $842(96.23 \%)$ & \\
\hline Yes & $172(4.15 \%)$ & $33(3.77 \%)$ & \\
\hline Indoor decoration during pregnancy & & & 0.147 \\
\hline No & $4130(99.81 \%)$ & $871(99.54 \%)$ & \\
\hline Yes & $8(0.19 \%)$ & $4(0.46 \%)$ & \\
\hline Single umbilical artery & & & 0.108 \\
\hline No & $4112(99.11 \%)$ & $862(98.51 \%)$ & \\
\hline Yes & $37(0.89 \%)$ & $13(1.49 \%)$ & \\
\hline Persistent right umbilical vein & & & 0.41 \\
\hline No & $4114(99.16 \%)$ & $870(99.43 \%)$ & \\
\hline Yes & $35(0.84 \%)$ & $5(0.57 \%)$ & \\
\hline
\end{tabular}

\section{Different types of fetal CHD in the case group}

Among the cases of fetal CHD, the top three types are congenital anomaly of a ventricle or the ventricular septum, ventriculo-arterial connection and the great arteries, including the arterial duct. In addition, critical CHDs account for $27 \%$, of which Tetralogy of Fallot is the most (7.1\%), followed by coarctation of aorta (4.0\%), Double-outlet right ventricle (2.9\%), D-transposition of the great arteries $(2.5 \%)$, and Pulmonary atresia with intact septum (2.1\%) (Table 2). 
Table 2

Different types of fetal critical CHD in the case group

\begin{tabular}{|ll|}
\hline Types of fetal CHD & $\mathbf{N}(\%)$ \\
\hline Overall CHD & $875(100 \%)$ \\
\hline Critical CHDs & $236(27.0 \%)$ \\
\hline Tetralogy of Fallot & $62(7.1 \%)$ \\
\hline Coarctation of the aorta & $35(4.0 \%)$ \\
\hline Double-outlet right ventricle & $25(2.9 \%)$ \\
\hline D-transposition of the great arteries & $22(2.5 \%)$ \\
\hline Pulmonary atresia with intact septum & $18(2.1 \%)$ \\
\hline Single ventricle & $16(1.8 \%)$ \\
\hline Total anomalous pulmonary venous connection & $15(1.7 \%)$ \\
\hline Hypoplastic left heart syndrome & $11(1.3 \%)$ \\
\hline Interrupted aortic arch & $11(1.3 \%)$ \\
\hline Truncus arteriosus & $9(1.0 \%)$ \\
\hline Ebstein anomaly & $8(0.9 \%)$ \\
\hline Tricuspid atresia & $4(0.5 \%)$ \\
\hline CHD: congenital heart disease & \\
\hline
\end{tabular}

\section{Logistic regression analysis of factors related to fetal congenital heart disease}

Forward stepwise regression analysis has shown that there are several factors positively related to the increased risk of fetal heart disease, namely gravidity $(\mathrm{OR}=1.32,95 \% \mathrm{Cl} 1.21-1.43, \mathrm{P}=0.000)$, upper respiratory tract infection during early pregnancy $(\mathrm{OR}=1.30,95 \% \mathrm{Cl} 1.04-1.63, \mathrm{P}=0.021)$, mental stress during early pregnancy $(\mathrm{OR}=2.87,95 \% \mathrm{Cl} 1.35-5.92, \mathrm{P}=0.006)$, single umbilical artery $(\mathrm{OR}=2.46,95 \% \mathrm{Cl}$ 1.24-4.85, $\mathrm{P}=0.010)$, and spouse smoking $(\mathrm{OR}=1.20,95 \% \mathrm{Cl} 1.00-1.45, \mathrm{P}=0.048)$ (Table 3$)$. 
Table 3

Logistic regression analysis of factors related to fetal congenital heart disease

\begin{tabular}{|c|c|c|c|c|c|c|c|}
\hline \multirow[t]{2}{*}{ Variables } & \multirow[t]{2}{*}{ B } & \multirow[t]{2}{*}{ SE } & \multirow[t]{2}{*}{ Wald } & \multirow[t]{2}{*}{ OR } & \multicolumn{2}{|c|}{$95 \% \mathrm{Cl}$} & \multirow{2}{*}{$\begin{array}{l}\mathrm{P} \text { - } \\
\text { value }\end{array}$} \\
\hline & & & & & Lower & Upper & \\
\hline Gravidity & 0.274 & 0.043 & 40.164 & 1.315 & 1.208 & 1.432 & 0.000 \\
\hline $\begin{array}{l}\text { Upper respiratory tract infection in } \\
\text { early pregnancy }\end{array}$ & 0.263 & 0.114 & 5.342 & 1.301 & 1.041 & 1.626 & 0.021 \\
\hline $\begin{array}{l}\text { Mental stress during early } \\
\text { pregnancy }\end{array}$ & 1.039 & 0.377 & 7.604 & 2.827 & 1.351 & 5.918 & 0.006 \\
\hline Spouse smoking & 0.186 & 0.094 & 3.905 & 1.204 & 1.002 & 1.447 & 0.048 \\
\hline Fetal single umbilical artery & 0.898 & 0.347 & 6.684 & 2.455 & 1.243 & 4.851 & 0.010 \\
\hline Constant & -0.411 & 0.326 & 1.586 & 0.663 & - & - & 0.208 \\
\hline
\end{tabular}

\section{Discussions}

This cross-sectional study analyzes factors related to fetal CHD based on our maternal-fetal database, with 875 cases of CHD fetuses among 5024 subjects from May 2018 to September 2019. The results of this research have revealed that there are several factors independently associated with an increased risk of fetal CHD, including gravidity, upper respiratory tract infection during early pregnancy, mental stress during early pregnancy, parental smoking, and fetal single umbilical artery. Among them, mental stress of pregnant women during pregnancy is associated with higher risk of CHD, followed by fetal single umbilical artery and gravidity.

Mental stress and upper respiratory tract infection during pregnancy are common maternal comorbidities associated with fetal CHD, which has also been reported in previous studies. One of the studies was from Shandong, China, which pointed out several environmental risk factors related to CHD, including maternal upper respiratory tract infection $(\mathrm{OR}=4.12)$ and maternal mental stress $(\mathrm{OR}=3.93)$ during early pregnancy, as well as number of previous pregnancies $(O R=2.68)[10]$. In 2019 , another study has reported that these three factors can increase the risk of $\mathrm{CHD}$ by about 2 times using an artificial neural network prediction model [11]. In other research on the association between mental stress and CHD, the evaluation of mental stress is often based on several questions. However, the mental stress mentioned in this study is only derived from the self-experience of the respondents in the questionnaire, so it is not clear to define the degree of mental stress experienced by pregnant women. Although the role of maternal stress needs to be validated by additional studies, and the biological mechanisms by which maternal stress causes $\mathrm{CHD}$ are not clear, we strongly suggest that psychological management for pregnant women be strengthened, especially during early pregnancy. As for maternal viral infection, we first talk about another study, which provide new enforced evidence that maternal upper respiratory tract infection/influenza during early pregnancy, in general, play an important role in the occurrence of CHD 
[12]. In addition, there is a meta-analysis [13] of maternal viral infection and increased risk of fetal CHD, which suggested that mothers who had a history of viral infection in early pregnancy had a significantly higher risk of having offspring with $\mathrm{CHD}(\mathrm{RR}=2.28)$, and this risk was more significant in mothers with rubella and cytomegalovirus. The effect of nonspecific maternal infection is difficult to definitively separate from the effects of medications used to treat the illness, including maternal fever and infection. Jenkins et al reported an up to 1.9-fold increase in the risk of aggregate cardiac defects in patients with maternal febrile illness and a 1.1-fold increase in the rate of any heart defects among subjects with maternal influenza infection in early pregnancy[14]. The results of these studies are consistent with ours. However, the viruses were not classified in detail in our study.

Regarding the number of pregnancy related to the increased risk of fetal CHD, although the exact mechanism is unknown, it might be related to spontaneous abortion. China has opened the second child policy in 2016. Before that, multiparity has been limited. However, the causal relationship between spontaneous abortion and CHD could not be inferred according to current knowledge, and these results only indicate that a history of miscarriage is a predictor of having an infant born with $\mathrm{CHD}$ or an increased risk of tetralogy of Fallot [15]. In any case, these findings suggest that the management of obstetric healthcare and counseling for women with a history of miscarriages should be strengthened to reduce the incidence of $\mathrm{CHD}$.

The correlation between paternal smoking and congenital cardiovascular defects has been studied, but too little information is available to determine the associated risk. Of the many congenital defects observed in a nursery, there was a significantly higher incidence of cardiovascular system abnormalities in the tobacco-exposed group [16]. A case-control study [17] suggested that there is an association between periconceptional tobacco exposure and an increased risk of $\mathrm{CHD}$ during the neonatal period and that there may be a dose effect; however, this needs to be confirmed in a larger population. Unfortunately, in our study, we were not able to verify this dose-effect relationship, although our results do suggest that paternal smoking is a risk factor for CHD. The potential mechanisms underlying the teratogenicity associated with periconceptional tobacco exposure remain unclear. One possible reason is that nicotine and carbon monoxide damage placental functions, leading to fetal hypoxia $[18,19]$.

The association between maternal diabetes and an increased risk of CHD has been clearly described in many studies [6, 20,21]. However, no similar finding was achieved in our research. This may be because of selection bias in the population recruited in our center because many pregnant women with diabetes are referred to our center from local hospitals for fetal echocardiography, and most of these fetuses are normal, resulting in a nonrandomly selected population. This could further affect our conclusions.

With regard for fetal factors, we found that there was a correlation between single umbilical artery and fetal CHD. Single umbilical artery is one of the most common human umbilical malformations, with an incidence of $0.55-4.85 \%$ [22], while the proportion in our population is $1 \%$. Previous studies have demonstrated an increased prevalence of $\mathrm{CHD}$ in fetuses with an single umbilical artery in the presence of additional risk factors for $\mathrm{CHD}[23,24]$. All these results have suggested the indication of fetal 
echocardiography for the fetuses with single umbilical artery. Compared with existing research, our conclusions are consistent with it, but the sample size of our study is much larger than that of related studies.

There are several advantages and limitations in this study. We analyzed factors related to fetal CHD for the first time with such a complete and huge database in China. The large sample size makes the conclusions of this study more stable and more convincing. We did consider as many factors as possible with CHD. As is known to us that CHD is a multifactorial complex disease, but we have to admit that we have not refined the assessment of the interactions between the various factors and also failed to take into account all the factors that cause CHD. Another strength of the study is the fact that we examine fetal CHD as opposed to only live births and thus would capture pregnancies who would go on to have intrauterine demise or termination that would not be captured in a neonatal/live birth registry. We acknowledge that although it was based on a large population, the data were mainly obtained from selfreported questionnaires, and the accuracy of information collection is therefore a problem that needs to be considered. Moreover, this is a cross-sectional study that demonstrates only the correlations between these factors and fetal CHD but does not provide causal relationships. One additional limitation is that our center is a referral center for fetal heart disease. The fetuses referred to our center come from all over the country. Therefore, some of the patients coming to our center are pregnant women with known risk factors or with a fetus previously found to have CHD at a local hospital, and this may have led to selection bias in the population. In addition, fetal CHD was diagnosed by fetal echocardiography and we didn't make postnatal verification for every case. But our findings can be credible, because fetal echocardiographic diagnoses were mostly consistent with autopsy findings in our center, which has shown that fetal cardiovascular anomalies disclosed by FE were completely in line with autopsy findings in nearly $99 \%$ of cases[9]. A final limitation may be that the relationships between genetic factors and fetal CHD were not considered in this study, which is solely focused on clinical characteristics. Considering the above factors, our findings should be interpreted cautiously and may not be generalizable to all patients.

In conclusion, we have found that there were several factors independently associated with fetal CHD, including gravidity, upper respiratory tract infection and mental stress during early pregnancy, parental smoking and fetal single umbilical artery. Thus, the $\mathrm{CHD}$ risk can be alleviated by reducing the exposure to environmental risk factors. Augmenting maternal mental healthcare, obtaining regular health counseling and testing during pregnancy, preventing upper respiratory tract infections and mental stress, offering health promotion and health education to women of childbearing age (especially those with less formal education), and improving obstetric procedures and techniques may lower the occurrence of CHD.

\section{Abbreviations}

CHD

Congenital heart disease

AHA

Page 13/16 
American Heart Association

$\mathrm{GW}$

gestational weeks

ISUOG

International Society of Ultrasound in Obstetrics and Gynecology

LVOT

left ventricular outflow tract

RVOT

right ventricular outflow tract

IQR

interquartile range

OR

odd ratio

$\mathrm{Cl}$

confidence interval

\section{Declarations}

\section{Acknowledgement}

Not applicable.

\section{Authors' contributions}

YH supervised the study and performed statistical analysis of the data. YR was conceived the study and wrote the main body of the manuscript. ZX participated in the discussion on the interpretation of the research content and involved in the procedure. XL revised the paper. All authors read and approved the final manuscript.

\section{Funding}

The work was supported by National Key R\&D Program of China (2018YFC1002300) and Yantai Science and Technology Innovation Development Project (2021YD018).

\section{Availability of data and materials}

The datasets used during the current study are available from the corresponding author on reasonable request.

\section{Ethics approval and consent to participate}

All participants provided written consent before entering the study. The study was approved by the Ethics Committee of Beijing Anzhen Hospital, Capital Medical University $₫$ with the ethical Approval Number: 
2022060X. We can confirm that all methods for the acquisition of fetal echocardiographic images was performed according to the guidelines and standards of the AHA [6] and the International Society of Ultrasound in Obstetrics and Gynecology (ISUOG) [8].

\section{Consent for publication}

Not applicable.

\section{Competing interests}

All authors declare that they have no competing interests.

\section{References}

1. GBD 2017 Congenital Heart Disease Collaborators.Global, regional, and national burden of congenital heart disease, 1990-2017: a systematic analysis for the Global Burden of Disease Study 2017. Lancet Child Adolesc Health. Lancet Child Adolesc Health 2020;4(3):185-200.

2. Zhao QM, Liu F, Wu L, et al. Prevalence of Congenital Heart Disease at Live Birth in China. J Pediatr 2019; 204:53-58.

3. Tennant PW, Pearce MS, Bythell M, et al. 20-year survival of children born with congenital anomalies: a population-based study. Lancet 2010;375(9715):649-656.

4. Wren C, Irving CA, Griffiths JA, et al. Mortality in infants with cardiovascular malformations. Eur J Pediatr 2012;171(2):281-287.

5. Bruneau BG. The developmental genetics of congenital heart disease. Nature 2008 21;451(7181):943-948.

6. Donofrio MT, Moon-Grady AJ, Hornberger LK, et al. Diagnosis and treatment of fetal cardiac disease: a scientific statement from the American Heart Association. Circulation 2014;129(21):2183-2242.

7. American College of Obstetricians and Gynecologists. ACOG Practice Bulletin No. 95: anemia in pregnancy. Obstet Gynecol 2008;112(1):201-207.

8. International Society of Ultrasound in Obstetrics and Gynecology, Carvalho JS, Allan LD, Chaoui R, et al. ISUOG Practice Guidelines (updated): sonographic screening examination of the fetal heart. Ultrasound Obstet Gynecol 2013;41(3):348-359.

9. Gao S, Han J, Yu S, et al. Comparison of fetal echocardiogram with fetal cardiac autopsy findings in fetuses with congenital heart disease. J Matern Fetal Neonatal Med 2019; 12:1-7.

10. Liu S, Liu J, Tang J, et al. Environmental risk factors for congenital heart disease in the Shandong Peninsula, China: a hospital-based case-control study. J Epidemiol 2009;19(3):122-130.

11. Li H, Luo M, Zheng J, et al. An artificial neural network prediction model of congenital heart disease based on risk factors: A hospital-based case-control study. Medicine (Baltimore) 2017;96(6):e6090.

12. Xia $Y Q$, Zhao KN, Zhao AD, et al.Associations of maternal upper respiratory tract infection/influenza during early pregnancy with congenital heart disease in offspring: evidence from a case-control 
study and meta-analysis. BMC Cardiovasc Disord. 2019;19(1):277.

13. Ye Z, Wang L, Yang T, et al. Maternal Viral Infection and Risk of Fetal Congenital Heart Diseases: A Meta-Analysis of Observational Studies. J Am Heart Assoc 2019;8(9):e011264.

14. Jenkins KJ, Correa A, Feinstein JA, et al. Noninherited risk factors and congenital cardiovascular defects: current knowledge: a scientific statement from the American Heart Association Council on Cardiovascular Disease in the Young: endorsed by the American Academy of Pediatrics.Circulation 2007;115(23):2995-3014.

15. Tikkanen J, Heinonen OP. Congenital heart disease in the offspring and maternal habits and home exposures during pregnancy. Teratology 1992; 46(5):447-454.

16. Woods SE, Raju U. Maternal smoking and the risk of congenital birth defects: a cohort study.J Am Board Fam Pract 2001;14(5):330-334.

17. Karatza AA, Giannakopoulos I, Dassios TG, Belavgenis G, Mantagos SP, Varvarigou AA.

Periconceptional tobacco smoking and isolated congenital heart defects in the neonatal period. Int $\mathrm{J}$ Cardiol 2011;148(3):295-299.

18. Rogers JM. Tobacco and pregnancy. Reprod Toxicol 2009; 28(2):152-160.

19. Shi M, Wehby GL, Murray JC. Review on genetic variants and maternal smoking in the etiology of oral clefts and other birth defects. Birth Defects Res C Embryo Today 2008;84(1):16-29.

20. Chou HH, Chiou MJ, Liang FW, et al. Association of maternal chronic disease with risk of congenital heart disease in offspring. CMAJ 2016;188(17-18):E438-E46.

21. Liu S, Joseph KS, Lisonkova S, et al. Association between maternal chronic conditions and congenital heart defects: a population-based cohort study.Circulation 2013;128(6):583-589.

22. Thummala MR, Raju TN, Langenberg P. Isolated single umbilical artery anomaly and the risk for congenital malformations: A meta-analysis. J Pediatr Surg 1998; 33: 580-585.

23. Chen K, Akoma U, Anderson A, Mertz H, Quartermain MD.Prenatally diagnosed single umbilical artery: The role and relationship of additional risk factors in the fetus for congenital heart disease. $\mathrm{J}$ Clin Ultrasound 2016;44(2):113-117.

24. Wang $\mathrm{J}, \mathrm{Ye} Y$, Xin T, et al.Is echocardiography necessary for all single umbilical artery fetuses? A retrospective study in a selected Chinese population. J Obstet Gynaecol Res 2019;45(4):803-809. 